\title{
Experiência do usuário e Design de Sistema Produto-Serviço: Uma reflexão sobre a contribuição da Psicologia Cognitiva
}

\section{User experience and Product-Service System design: Discussion about the Cognitive Psychology contribution}

Gabriel Gallina Jorge ${ }^{1}$

Filipe Campelo Xavier da Costa ${ }^{2}$ 


\section{Resumo}

O Design de Sistema Produto-Serviço abrange a criação de artefatos e suas inter-relações, considerando dimensões tangíveis e intangíveis na estratégia de composição de uma determinada oferta. Para isso, é recomendável que o designer conheça o que o usuário pensa a respeito dos componentes desta oferta para, em projeto, encaminhar decisões coerentes às suas demandas. Porém, as metodologias de Design de SPS não tratam com objetividade a maneira de utilizar dados sobre o usuário, tampouco são claras quanto a forma de dar seu devido endereçamento ao projeto. Neste artigo analisamos um panorama dos métodos de Design de SPS existentes na literatura e que são orientados para a pesquisa sobre o usuário, e fazemos uma reflexão sobre como preencher esta lacuna através da Psicologia Cognitiva e sua Teoria dos Appraisals. Apresentamos como alcançar um entendimento qualificado sobre o usuário através da aplicação do Perfil de Concerns, recurso que instrumentaliza o designer para traduzir de maneira adequada dados do usuário e como aplicá-los em projeto de SPS.

Palavras-chave: design; sistema produto-serviço; teoria dos appraisals; perfil de concerns.

\section{Abstract}

Product-Service System Design covers the artifacts creation and their interrelations, considering tangible and intangible dimensions in the offer strategies. It's recommended that the designer knows what the user thinks about the components of this offer, in order to forward decisions coherent to their demands. However, PSS Design methodologies don't deal objectively about how to use user data, nor are clear about how to properly address this to the project. In this article we analyze a bibliographic panorama of PSS's Design methods that are oriented to the research on the user, and we reflect how to fill this gap through Cognitive Psychology and its Appraisals Theory. We present how to achieve a qualified understanding of the user through the application of the Concerns Profile, a feature that improve the designer to translate adequately user data and apply them in a PSS project.

Key-words: design; product-service system; appraisals theory; concern profile.

${ }^{1}$ Mestre em Design, Unisinos (arq.gallina@gmail.com)

${ }^{2}$ Doutor em Administração, Unisinos (fcampelo@unisinos.br) 


\section{INTRODUÇÃO}

A entrega de um Sistema Produto Serviço - SPS consiste na criação de artefatos e suas amarrações enquanto sistema, e considera dimensões materiais e imateriais na composição da oferta que chegará ao usuário. A solução assume contornos muito sensíveis ao contexto, pois é determinada pelas características culturais, sociais e econômicas destes usuários, bem como dos atores e dos aspectos tecnológicos envolvidos na sua construção (MORELLI, 2002). Enquanto tais aspectos tecnológicos são mais familiares ao universo do designer, o entendimento do usuário varia conforme o projeto. Compreender quem é e o que deseja este usuário passa a ser uma discussão relevante para o Design, e, principalmente, crucial para o sucesso de um SPS. Por isso, alguns autores (MORELLI, 2003; BAINES et al, 2007) sugerem que este tipo de projeto seja pensado a partir da perspectiva do usuário.

É possível tomar conhecimento do usuário e suas características através de pesquisas qualitativas e quantitativas. Entretanto a literatura que trata das metodologias de Design de SPS não é clara sobre como o designer deve lidar com estes dados. Percebemos uma lacuna no processo, justamente no momento em que o designer analisa e endereça os dados do usuário para seu projeto. Diante disso, levantamos uma questão: Como estruturar e tratar os dados de pesquisa de modo que organizem as necessidades do usuário para, em seguida, abastecer diretrizes de projeto de um SPS?

Esta conexão entre as etapas de investigação do usuário e a de projeto de design pode se dar de várias maneiras. Uma delas é oferecida pela Psicologia Cognitiva, que diz que, para atender o usuário, precisamos antes entender como este faz seu julgamento sobre algo (DESMET, 2002). Este campo do conhecimento nos oferece recursos importantes através da Teoria dos Appraisals. Esta teoria diz que as emoções correspondem ao resultado combinado das predisposições do indivíduo (concerns) diante de um estímulo (artefatos). Esta combinação provoca um processo de avaliação (appraisal) no indivíduo, que então responderá com uma emoção. Assim, é possível afirmar que, sabendo identificar estes concerns, o designer consegue dirigir de maneira adequada su a proposta de projeto para que esta os atenda (OZKARAMANLI et al, 2014). A Teoria dos Appraisals permite não só uma compreensão qualificada a respeito do usuário, ela também instrumentaliza o designer para que este a aplique como insumo em seu projeto (TONETTO, 2012; TONETTO; COSTA, 2011; DEMIR et al, 2009; DESMET, 2002).

Este artigo se propõe a discutir de que maneira este processo pode ser elaborado, considerando, para isso, a construção de um Perfil de Concerns. Este perfil é um documento que apresenta afirmativas de concerns vindas do usuário - eu quero, eu gosto, eu desejo, eu preciso - organizadas por agrupamentos semânticos e com trechos das falas dos entrevistados, provenientes de entrevistas em profundidade. Acessar este documento facilita o desenvolvimento de diretrizes que nortearão a etapa projetual, provocando no designer insights criativos e que tem forte relação com as necessidades reais do usuário (DEMIR et al, 2010; TONETTO, 2012). Através de um panorama teórico que relaciona SPS, Design de SPS e Teoria dos Appraisals, o artigo conclui sugerindo a aplicação do Perfil de Concerns de maneira adaptada a um SPS. 


\section{A PERSPECTIVA DO USUÁRIO NO DESIGN DE SPS}

O conceito de Sistema Produto-Serviço, ou SPS, emerge da necessidade de relacionar aspectos tangíveis e intangíveis a partir de uma perspectiva sistêmica, resultando em uma entrega conjunta, mais completa e qualificada. A oferta assume maior complexidade e passa a requerer o desenvolvimento de abordagens multidisciplinares, como economia, gestão, estudos ambientais, sociologia, psicologia, design de produto e engenharia. (MONT, 2006).

O desenvolvimento de um SPS representa um grande desafio por deslocar o foco das atividades que envolvem o produto ou serviço isolado, focando na orquestração de um sistema de componentes. Para Morelli $(2003$, p.4) "este sistema deve ser contemplado de modo que todos os seus componentes recebam a devida atenção e tenham a mesma relevância, sejam eles tangíveis ou intangíveis".

A perspectiva do Design enfatiza alguns elementos-chave para a concepção do SPS, como: (i) a análise cultural, técnica e social aos quais estão relacionados os componentes do SPS; (ii) a análise da perspectiva do usuário e seus requisitos sociais e culturais; (iii) a análise dos padrões de uso; e (iv) a proposição de novos valores para o serviço (MORELLI, 2003). A capacidade de enfatizar estas questões certamente não é exclusiva do Design, entretanto a abordagem do Design permite a visualização destas questões.

Nicola Morelli é reconhecidamente uma referência na pesquisa sobre métodos e instrumentos associados a esta abordagem sistêmica, especialmente nos aspectos que tocam ao usuário (KIM et al, 2011). Este autor entende que o processo projetual de um SPS pode ser assim esquematizado (Figura 1).

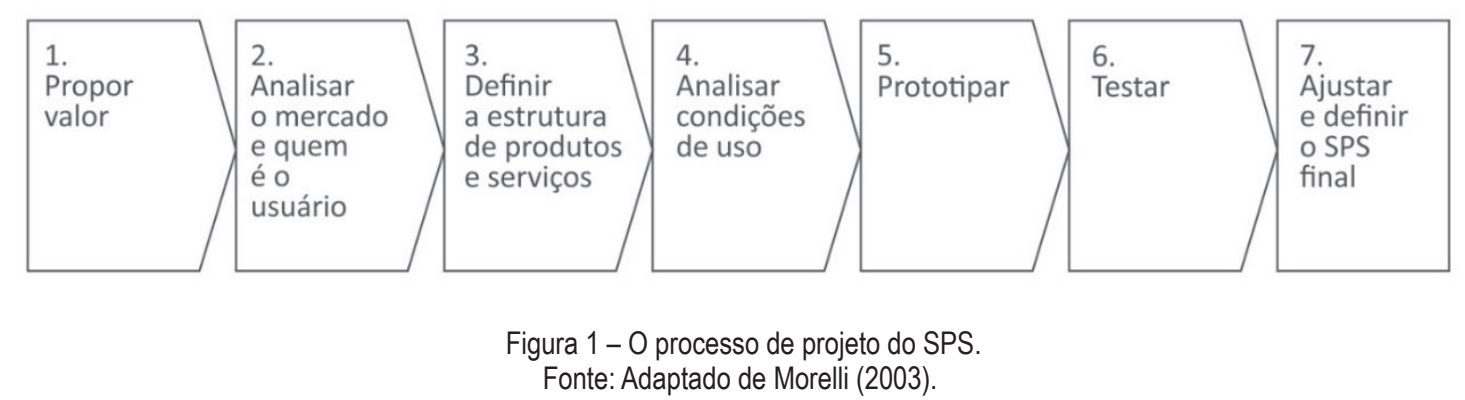

Kim et al (2011, p.9) consideram que "para apoiar de maneira eficaz o processo de desenvolvimento do SPS, é necessário adequar e desenvolver instrumentos apropriados conforme a situação ou contexto em este está inserido". Mais do que identificar os atores da rede que integra o SPS, o papel do designer avança na compreensão de suas características e necessidades para, em um segundo instante mais operacional, desenvolver a orquestração de suas relações enquanto sistema. Através de abordagens adequadas de pesquisa é possível identificar o perfil do usuário e suas necessidades.

Ao mesmo tempo que a importância do usuário fica sendo evidenciada, a forma como se analisam os dados a seu respeito é pouco definida. Abaixo, apresentamos um quadro de referências que expõe as formas de coleta de dados dos usuários e como as informações são usadas em projetos. 


\begin{tabular}{|c|c|c|}
\hline Autor & $\begin{array}{l}\text { Como propõe a captura das } \\
\text { informações sobre o usuário }\end{array}$ & $\begin{array}{l}\text { Como propõe a utilização } \\
\text { destas informações no projeto }\end{array}$ \\
\hline Kim, E. et al (2016) & $\begin{array}{l}\text { Divide em pesquisa de } \\
\text { comportamento, pesquisa de } \\
\text { atitudes, métodos qualitativos e } \\
\text { quantitativos. }\end{array}$ & $\begin{array}{l}\text { "O processo de design consiste } \\
\text { em uma pesquisa formativa, } \\
\text { para confirmação do problema; } \\
\text { e uma pesquisa sumária, para } \\
\text { interpretar os outputs do } \\
\text { processo de investigação" (p.3). }\end{array}$ \\
\hline
\end{tabular}

\begin{tabular}{|c|c|c|}
\hline Andriankaja, H. et al (2016) & Elabora uma análise de uso. & $\begin{array}{l}\text { "A análise de uso é combinada } \\
\text { com cenários, para verificar } \\
\text { diferentes usos da oferta de } \\
\text { SPS, a fim de identificar o } \\
\text { potencial de criação de valor } \\
\text { para os clientes. Para isso, } \\
\text { é necessário categorizar os } \\
\text { clientes, seus costumes e suas } \\
\text { necessidades em termos de } \\
\text { produto e serviços e cruzar } \\
\text { com oportunidades do SPS" } \\
\text { (p.3). }\end{array}$ \\
\hline Kimita, K.; Shimomura, Y. (2014) & $\begin{array}{l}\text { Sugere um instrumento tipo } \\
\text { checklist de necessidades do } \\
\text { cliente. }\end{array}$ & $\begin{array}{l}\text { "Neste checklist as } \\
\text { necessidades dos clientes } \\
\text { são extraídas do ponto de } \\
\text { vista dos 'atores orientador } \\
\text { para o produto' e dos 'atores } \\
\text { orientados ao processo" } \\
\text { (p.345). }\end{array}$ \\
\hline Pezzotta, G. et al (2014) & $\begin{array}{l}\text { Pesquisa de mercado, } \\
\text { entrevista com o usuário, } \\
\text { grupos focais e consulta com } \\
\text { especialistas. }\end{array}$ & $\begin{array}{l}\text { "O objetivo é obter uma } \\
\text { compreensão clara das } \\
\text { necessidades dos clientes } \\
\text { e seus requisitos a respeito } \\
\text { de produtos, serviços e } \\
\text { expectativas. Esta análise pode } \\
\text { também levar à segmentação } \\
\text { dos clientes em categorias de } \\
\text { necessidades" (p.52). }\end{array}$ \\
\hline Carreira, R. et al (2013) & $\begin{array}{l}\text { Observação e entrevistas } \\
\text { semiestruturadas, que } \\
\text { oferecem insumos para } \\
\text { desenvolvimento de } \\
\text { questionários quantitativos. }\end{array}$ & $\begin{array}{l}\text { "Os resultados preliminares } \\
\text { são apresentados e } \\
\text { discutidos com a equipe de } \\
\text { especialistas, para lhes dar } \\
\text { uma perspectiva mais holística } \\
\text { da experiência do cliente } \\
\text { baseada no levantamento das } \\
\text { necessidades mais latentes. A } \\
\text { fim de permitir a utilização dos } \\
\text { dados, estes são combinados } \\
\text { e categorizados através } \\
\text { de software que considera } \\
\text { variáveis da Engenharia Kansei" } \\
\text { (p.748). }\end{array}$ \\
\hline
\end{tabular}




\begin{tabular}{lll}
\hline Akasaka, F. et al (2012) & $\begin{array}{l}\text { Sugere coletar e organizar } \\
\text { dados para especificar as } \\
\text { necessidades do cliente, mas } \\
\text { não menciona como. }\end{array}$ & $\begin{array}{l}\text { "Com base nas necessidades } \\
\text { identificadas, as ideias para } \\
\text { o SPS são geradas com, } \\
\text { por exemplo, técnicas de } \\
\text { brainstorming" (p.240). }\end{array}$ \\
\hline Morelli, N. (2002 e 2005) & $\begin{array}{l}\text { Uso de instrumentos para } \\
\text { identificação dos atores } \\
\text { envolvidos e suas necessidades, } \\
\text { como video-etnografia e } \\
\text { cultural probes. }\end{array}$ & $\begin{array}{l}\text { "O usuário é acionado direta } \\
\text { e contribuir no processo de } \\
\text { projeto" (p.5). }\end{array}$ \\
& & \\
\hline
\end{tabular}

Quadro 1 - Como a informação sobre o usuário é obtida e tratada. Fonte: Os autores

Percebemos, portanto, uma lacuna importante no processo de projeto do SPS. As metodologias de Design de SPS que atendem a perspectiva do usuário não tratam com objetividade o modo como ocorre a utilização dos dados de pesquisa. Diante da estrutura proposta por Morelli (2003), ilustramos esta lacuna na Figura 2.

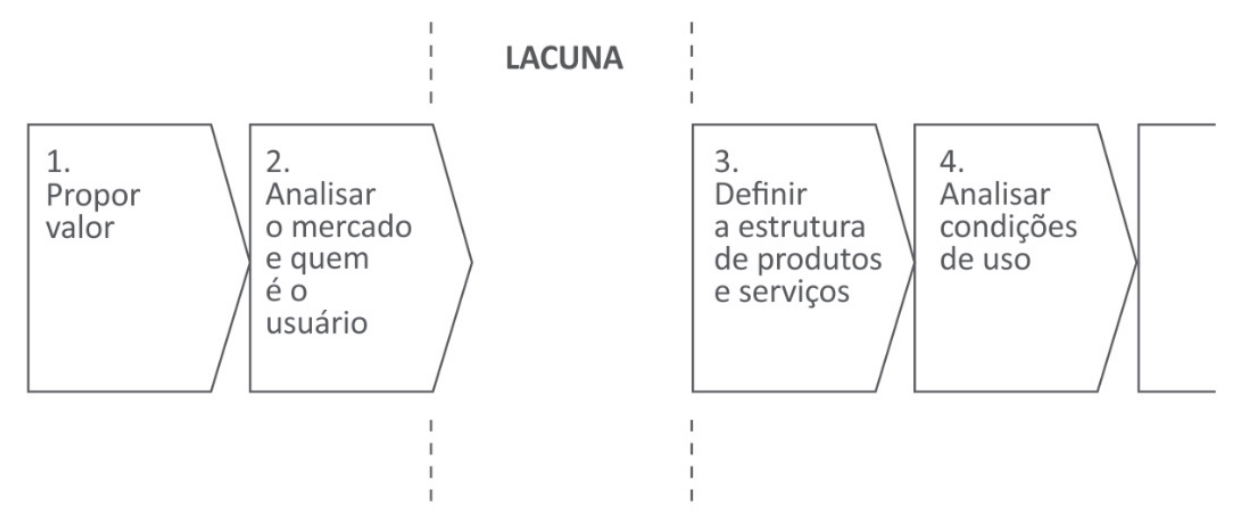

Figura 2 - A lacuna no processo de SPS.

Fonte: Os autores

Frente às diferentes dimensões e possíveis arranjos que o SPS requer, nem sempre a experiência prévia do designer lhe será suficiente para conceber e organizar de maneira adequada todo um sistema. Conforme observa Kimita et al (2009), quando desamparado de processos sistemáticos, o designer muitas vezes se faz valer de avaliações subjetivas.

Diante do que foi levantado, é possível confirmar que, operacionalmente, o Design de SPS não obedece a um padrão. A complexidade intrínseca deste tipo de projeto requer abordagens flexíveis que consigam lidar com aspectos narrativos e técnicos para definir sua estruturação. Esta observação vem ao encontro de Jones (1970, p.73), que afirma que "metodologias são o que são, meros arranjos simbólicos (...), não um traçado fixo para um destino fixo, mas uma conversação sobre tudo o que pode acontecer".

Considerando o que foi exposto até aqui, abre-se a perspectiva para a exploração de outras áreas transversais e relacionadas ao Design, como a Psicologia. A conexão entre as etapas de investigação do usuário e a de projeto de design pode se dar pela Psicologia Cognitiva, que diz que, para atender o usuário, precisamos antes entender como este faz seu julgamento sobre algo (DESMET, 2002). 


\title{
3 A CONTRIBUIÇÃO DA PSICOLOGIA COGNITIVA
}

Os processos de design lidam inicialmente com problemas mal definidos e que devem resultar, preferencialmente, na entrega de uma solução bem definida (CROSS, 2000). Para isso, o design se vale da sua transdisciplinaridade, característica que lhe permite integração com outros campos do conhecimento para, destes, extrair contribuições complementares aos seus propósitos. Para Tonetto e Costa (2011, p.133),

\begin{abstract}
O casamento entre psicologia e o design possibilitou (...) o desenvolvimento de metodologias que servissem como base para a certificação de que as emoções que se desejava provocar poderiam, de fato, ser obtidas por meio de projetos. A área é fortemente baseada em pesquisa direta com os usuários, de modo que a única forma de certificação de que o projeto atingiria seu êxito, com foco na emoção, é a aproximação do designer com o usuário e, portanto, com a atividade de pesquisa.
\end{abstract}

Assim, ao levar em consideração fundamentos da Psicologia e o amparo de dados de pesquisa, o designer tem a possibilidade de assumir uma postura mais embasada e segura diante dos desafios que lhe são propostos. Na Psicologia existem diversas teorias que explicam emoções, e que são organizadas de acordo com o que causa uma emoção. Neste artigo, a linha adotada se concentra no grupo de teorias dos Appraisals, que, por característica, tomam a emoção como uma equação composta de vários componentes como sentimentos, cognição, motivação e resposta somáticas e/ou motoras. Sua justificativa se dá pela aproximação já consolidada desta teoria cognitiva das emoções com o campo do design (TONETTO, 2012; TONETTO; COSTA, 2011; DEMIR et al, 2009; DESMET, 2002), e será melhor aprofundada a seguir.

\subsection{A Teoria dos Appraisals}

A perspectiva cognitiva nos diz que, para entender as emoções, é preciso antes entender como as pessoas fazem julgamentos sobre um determinado evento ou situação. Ou seja, a avaliação - ou appraisal - é algo que precede a emoção (DESMET, 2002; ROSEMAN; SMITH, 2001). No campo da Psicologia, as teorias que levam em consideração este processo são chamadas de Teorias dos Appraisals. Estas teorias encontram lugar no Design, sendo Pieter Desmet um dos autores que apresenta contribuição mais significativa a este campo. (DEMIR et al, 2009).

A proposta de Desmet (2002) consiste em trazer esta teoria para o Design através de sua aplicação prática. Em sua investigação, este autor analisa à luz da Teoria dos Appraisals de que maneira a aparência de um artefato evoca emoções. Considerando esta relação causal entre appraisals e emoções, pode-se afirmar que, ao ativar um determinado componente de appraisal, sua emoção correspondente igualmente será estimulada. Isso representa que, tendo o entendimento de quais componentes do appraisal provocam esta emoção padrão, a mesma possa ser então projetada (DEMIR et al, 2009).

Desmet sugere um modelo básico (Figura 3) possível de ser aplicado para res- 
ponder a todas as emoções eliciadas através da interação entre o usuário e um estímulo qualquer.

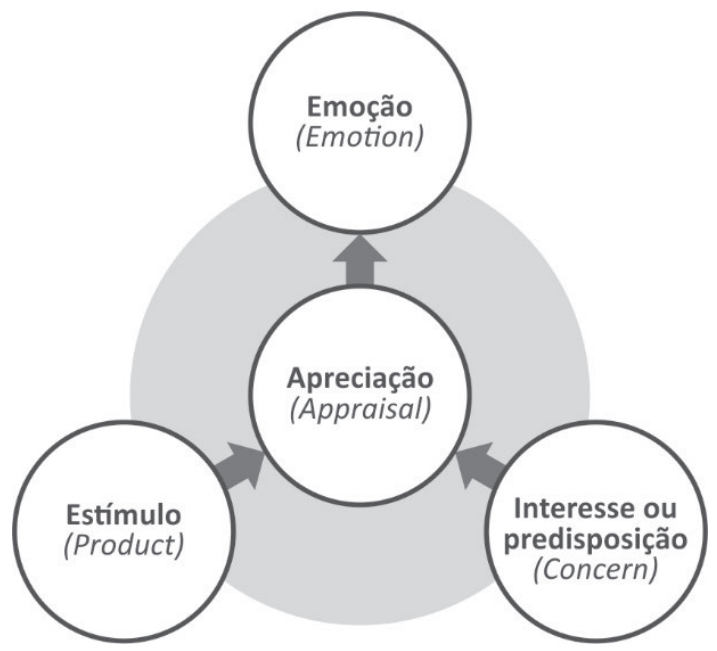

Figura 3 - Modelo básico da compreensão sobre emoções a partir de um estímulo. Fonte: Desmet (2002)

Este modelo proposto por Desmet (2002) sugere que as emoções emergem de três variáveis combinadas: as predisposições pessoais (concerns) de um indivíduo diante de um artefato (estímulo), cujo encontro formatará uma apreciação (appraisal) mental a respeito da capacidade deste artefato lhe oferecer benefícios ou prejuízos (DESMET, 2002). Para Desmet (2002) não há possibilidade de haver relação direta entre o design de um artefato e uma emoção, logo, o appraisal sempre deve ser considerado. Portanto, a emoção não é elicitada pelo artefato em si, mas, sim, pelo significado da avaliação (appraisal) feita pelas predisposições (concerns) do usuário diante do produto.

De acordo com a Teoria dos Appraisals, os concerns estão por trás de todas as emoções, pois "[...] são as pré-disposições que o indivíduo traz para o processo emocional". (DESMET; HEKKERT, 2007, p.62). Logo, uma maneira eficiente de projetar para emoção é projetar para os concerns. (OZKARAMANLI ET AL, 2014). Tonetto (2012, p.101) reforça esta passagem ao observar que "no design, mais que atentar para o processo psicológico das avaliações dos usuários (appraisals), os estudos comumente focam em análises de concerns.".

Na prática o designer levanta os concerns dos usuários através da pesquisa qualitativa (COSTA et al, 2012), e, a partir de sua análise de conteúdo, organiza estes concerns através de um Perfil de Concerns. O Perfil de Concerns é um documento que lista aquilo que é relevante ao usuário, estruturando a informação de modo que possa servir de inspiração ao processo criativo do designer (DEMIR et al, 2010). A seguir, apresentamos como este perfil pode ser elaborado a partir do contexto de um SPS.

\subsection{O Perfil de Concerns aplicado ao Design de SPS}

A construção de um Perfil de Concerns obedece uma sequência determinada. Primeiramente, a investigação parte do entendimento a respeito dos usuários. Este levantamento considera uma coleta de dados qualitativos primários, ou seja, obtidos 
através de questões abertas em conversa direta entre pesquisador e entrevistado. Os primeiros passos, portanto, atendem à elaboração de roteiro para entrevistas, seu pré-teste e devidos ajustes. Definida a versão final deste instrumento, procede-se com a seleção dos participantes e a realização das entrevistas em profundidade. A análise de conteúdo destas entrevistas buscará as afirmativas de concerns dos usuários - eu quero, eu gosto, eu prefiro - que denotam suas predisposições favoráveis e desfavoráveis ao SPS. A formatação de uma tabela organizando estas informações resultará no que chamamos de Perfil de Concerns, um documento objetivo quanto àquilo que o usuário deseja ou quer evitar.

Para observar este processo apresentamos sua aplicação no processo de design de um evento, em que o contexto analisado é o de um evento de comida de rua. Nota-se que, enquanto objeto de estudo, um evento de comida de rua aponta relações de fácil identificação com componentes de um SPS, assim como também toca em questões de organização e sistema. Podemos caracterizar a relação com SPS a partir da identificação de seus componentes, onde:

a) Sistema corresponde a uma percepção ampla do evento enquanto proposta conceitual, além de considerar aspectos de relação entre componentes;

b) Produto corresponde às ofertas do artefato comida e artefato bebida, considerando seus aspectos funcionais e estéticos, assim como os sensoriais envolvidos;

c) Serviço atende às questões de ordem operacional para acesso e disponibilização de aspectos tangíveis e intangíveis, como toda ação e infraestrutura que suporta os indivíduos presentes naquele evento, seja antes, durante ou depois de seu acontecimento;

d) Comunicação relaciona aspectos informacionais de promoção e divulgação do evento, assim como toda ocorrência paralela que se manifeste no plano virtual, como redes sociais e aplicativos para dispositivos móveis;

Por apresentar condições de ser enquadrado como algo de natureza planejada, é possível então propor a análise de como se daria o processo de sua concepção. Para ilustrar este exemplo, elaboramos o Perfil de Concerns a partir de uma pesquisa com usuários de eventos de comida de rua.

A pesquisa original teve características exploratórias, com o objetivo de conhecer os usuários e elaborar um Perfil de Concerns. Através de entrevistas em profundidade com frequentadores e não-frequentadores, levantou-se como estes indivíduos percebem e se relacionam com os eventos de comida de rua. Embora lidemos com informações qualitativas dos usuários, o objetivo não está na discussão ou compreensão da natureza individual de cada um de seus concerns, mas, sim, em organizar insumos para abastecer as etapas seguintes de projeto.

Estas entrevistas ocorreram em uma grande capital brasileira, durante o segundo semestre de 2016. Os participantes das entrevistas em profundidade foram selecionados por conveniência a partir da questão filtro 'Você esteve em um evento de comida de rua no último ano?'. Para fins desta pesquisa, delimitou-se o espaço temporal de um ano, a fim de atingir memórias recentes sobre suas experiências nestes eventos. Ao todo foram entrevistadas 13 pessoas com idade entre 24 e 43 anos, com grau superior completo e de formação profissional diversa. O número de entrevista- 
dos foi delimitado por saturação'.

As entrevistas foram transcritas na íntegra pelos próprios autores, a fim de identificar as afirmativas de concerns e suas nuances na fala de cada entrevistado. A partir destas transcrições, é iniciado o processo de análise de conteúdo em que foram destacados trechos representativos dos concerns como unidades de análise.

A partir das unidades de análise foram feitos agrupamentos por semelhança conceitual. Cada agrupamento foi identificado como uma categoria, criando-se para ela uma curta definição. Objetivamente, o processo de construção do Perfil de Concerns se deu da seguinte maneira:

a) Identificação das afirmativas de concerns mais recorrentes entre as unidades de análise do documento de análise de conteúdo;

b) Adequação do conteúdo da unidade de análise para uma redação mais clara e objetiva enquanto afirmativa de concerns, sem expressões emocionais e manifestações de intensidade;

c) Organização destas informações em uma tabela, com macro-categorias, categorias, as afirmativas de concerns com um fragmento exemplo, este vindo das próprias entrevistas, e sua relação com os componentes de SPS.

O Perfil de Concerns original conta com 14 macro-categorias e 74 categorias de concerns. Essas categorias foram definidas a partir da análise dos seus conteúdos temáticos e de semelhança quanto aos elementos relativos ao sistema, serviços e produtos de um evento de comida de rua. Trazemos neste artigo um trecho deste perfil que ilustra o resultado do processo acima explicado (Quadro 2).

\begin{tabular}{|c|c|c|c|c|}
\hline $\begin{array}{l}\text { Macro- } \\
\text { categoria }\end{array}$ & Categoria & $\begin{array}{l}\text { Afirmativa de } \\
\text { concern }\end{array}$ & $\begin{array}{l}\text { Trecho da fala do } \\
\text { entrevistado }\end{array}$ & $\begin{array}{l}\text { Componente de } \\
\text { SPS }\end{array}$ \\
\hline Atendimento & Rapidez & $\begin{array}{l}\text { Eu exijo ser } \\
\text { servido com } \\
\text { rapidez }\end{array}$ & $\begin{array}{l}\text { Pra mim sempre foi } \\
\text { rápido, e eu acho que é } \\
\text { uma coisa que deve ser } \\
\text { rápida né, o foodtruck } \\
\text { tá ali, a comida tá sendo } \\
\text { feita. (AC) }\end{array}$ & Serviço \\
\hline
\end{tabular}




\begin{tabular}{|c|c|c|c|c|}
\hline \multirow[b]{2}{*}{ Comida } & Chef & $\begin{array}{l}\text { Prefiro comida } \\
\text { preparada por um } \\
\text { chef }\end{array}$ & $\begin{array}{l}\text { (...) eu acho que tem } \\
\text { coisas melhores, mais } \\
\text { opções e coisas diferentes } \\
\text { e melhores pra comer. Daí } \\
\text { eu gosto mais. Tem uma } \\
\text { coisa mais de chefs, assim, } \\
\text { melhor apresentado. (TM) }\end{array}$ & Produto \\
\hline & Variedade & $\begin{array}{c}\text { Gosto de ver } \\
\text { a variedade de } \\
\text { opções de comida }\end{array}$ & $\begin{array}{l}\text { (...) Vai ter muitas opções } \\
\text { de comida, a gente não } \\
\text { precisa comer no mesmo } \\
\text { lugar(...). Que vai ter desde } \\
\text { o suco até a cerveja, a } \\
\text { sobremesa, o hamburger, } \\
\text { várias coisas diferentes. } \\
\text { (AC) }\end{array}$ & Produto \\
\hline \multirow[b]{2}{*}{ Apresentação } & Embalagem & $\begin{array}{c}\text { Desejo ver } \\
\text { embalagens } \\
\text { bonitas e bem } \\
\text { feitas }\end{array}$ & $\begin{array}{l}\text { Acho que pra mim o } \\
\text { que importa mais é a } \\
\text { apresentação da coisa, } \\
\text { sabe (...) se eu vejo uma } \\
\text { embalagem bonita e bem } \\
\text { montadinha. (TM) }\end{array}$ & Produto \\
\hline & Layout & $\begin{array}{l}\text { Prefiro ambientes } \\
\text { mais organizados }\end{array}$ & $\begin{array}{l}\text { (Ficaria mais tempo no } \\
\text { evento se tivesse) espaços } \\
\text { maiores, que tivesse mais } \\
\text { setorização, tipo 'ah, aqui } \\
\text { tem um lounge para todo } \\
\text { mundo ficar sentado', } \\
\text { ou 'ah, aqui é a área da } \\
\text { comida' (AC) }\end{array}$ & Sistema \\
\hline
\end{tabular}

Quadro 2. Perfil de concerns adaptado ao Design de SPS.

Fonte: Os autores

Tonetto (2012) salienta que uma análise de concerns só faz sentido no contexto onde ocorre e para os estímulos que geram tais concerns. Ou seja, não é recomendável que um perfil de concerns seja elaborado pelo designer sem apoio de pesquisa, nem tampouco seja replicado ou aproveitado de outro contexto.

Apresentado desta forma (Quadro 2) um perfil de concerns é considerado um verdadeiro suporte ao processo de projeto. Isto porque facilita e agiliza o acesso do designer às informações que balizarão e contribuirão com seu projeto, garantindo que este esteja orientado ao usuário. Neste sentido, o designer tem condições de planejar por onde inicia seu lançamento projetual, se pelo todo - o sistema - ou se por partes - os componentes. Independente de qual for seu caminho, espera-se que este perfil lhe ofereça a garantia de não negligenciar nenhum ponto importante ao usuário.

\section{CONSIDERAÇÕES FINAIS}

Diversos autores (DEMIR et al, 2010. OZKARAMANLI; DESMET, 2012. TONETTO, 2012) salientam que interpretar os concerns é um grande desafio. Objetivamente, trata-se de uma análise de conteúdo a partir da captação organizada de dados. Por mais preciso que esteja o roteiro de perguntas, a subjetividade das respostas pode apontar 
para caminhos incertos. Independentemente do delineamento destes concerns, entendemos que a elaboração deste perfil atende de modo adequado à necessidade do designer de valer-se de um meio para compreender a informação sobre o usuário e conseguir endereçá-la no projeto de SPS.

Além deste aspecto prático proporcionado pelo Perfil de Concerns, podemos apontar outros benefícios ao Design de SPS. Um deles diz respeito à assertividade dos resultados, pois saber antecipadamente quais são as predisposições do usuário tende a trazer mais segurança e objetividade para o processo criativo do designer, minimizando, assim, a probabilidade de insucesso de seus resultados projetuais (TONETTO, 2012). Outra vantagem recai no aspecto humanizado que o perfil de concerns confere ao processo de projeto, visto que propicia ao designer uma maior aproximação com o universo do usuário. Por fim, a própria estrutura do documento do perfil sugere uma visualização concisa e objetiva das necessidades do usuário, descomplicando o acesso à informação e liberando o designer da análise de documentos extensos e pouco práticos.

Finalizando, espera-se que com esta exemplificação de um caminho projetual termos contribuído para a compreensão da aplicação das abordagens aqui descritas. Ao compreender a lacuna entre pesquisa e projeto, propusemos sua conexão através do uso de recursos trabalhados pela psicologia cognitiva, tocando aspectos da sistematização da prática do design. Conforme visto, este esforço se mostra justificável sob diversos aspectos. Dentro das possibilidades de abordagem que cada situação projetual demanda, entendemos como válido todo e qualquer empenho em compreender melhor o usuário, assim como em facilitar o processo criativo do designer. Embora estas questões não representem, necessariamente, alcançar melhores resultados de projeto, é possível considerar que tornam o processo mais qualificado.

\section{REFERÊNCIAS}

AKASAKA, F.; NEMOTO, Y.; CHIBA, R. SHIMOMURA, Y. Development of PSS design support system: knowledge-based design support and qualitative evaluation. Procedia CIRP, v.3, p.239-244, 2012.

ANDRIANKAJA, H.; BOUCHER, X.; MEDINI, K.; VAILLANT, H. A Framework to design integrated product-service systems based on the extended functional analysis approach. Procedia CIRP, v.47, p.323-328, 2016.

BAINES, T.; LIGHTFOOT, H; EVANS, S; et al. State-of-the-art of product service-systems. Proc IMechE, v.221, Part B: J Engineering Manufacture, p.1-10. 2007.

CARREIRA, R; PATRICIO, L; JORGE, R. N.; MAGEE, C. Development of an extended Kansei engineering method to incorporate experience requirements in productservice system design. Journal of Engineering Design, vol. 24, n. 10, p.738-764, 2013.

CROSS, N. Engineering design methods: strategies for product design. 3a ed. Inglaterra: Ed John Wiley \& Sons, 2000. 
DEMIR, E.; DESMET, P.; HEKKERT, P. Appraisal patterns of emotions in human-product interaction. International Journal of Design, 3(2), p.41-51 2009.

DEMIR, E.; DESMET, P.; OZKARAMANLI, D. How to Design for Emotions: experiences in a course. in: SATO, K.; DESMET, P.; HEKKERT, P.; LUDDEN, G.; MATHEW, A. Proceedings of the International Design \& Emotion Conference. 2010.

DESMET, P. Designing emotions. 2002. Tese (Doutorado) - Delft University of Techonolgy, Delft. Holanda.

DESMET, P.; HEKKERT, P. Framework of product experience. International Journal of Design, 1 (1), p. 13-23, 2007.

FONTANELLA, B.J.B.; RICAS, J.; TURATO, E. R. Amostragem por saturação em pesquisas qualitativas em saúde: contribuições teóricas. Cad. Saúde Pública n. 24 (1). Rio de Janeiro: p.389-394, 2008.

JONES, J. C. Design methods: seeds of human futures. New York, John Wiley \& Sons, 1970.

KIM, E; LEE, K; NAM, K. Activity-driven PSS design method based on emotional customer activity modeling integrating expectation and experience factors. International Journal of Affective Engineering, v.15, n.3, p.265-277, 2016.

KIM, Y; LEE, S; LEE, J; HAN, D; LEE, H. Design support tools for product-service systems. Conference paper. International Conference on Engineering Design, ICED11. Dinamarca: Techincal University of Denmark, 2011.

KIMITA, K; SHIMOMURA, Y. Development of the design guideline for product-service systems. Procedia CIRP, v.16, p.344-349, 2014.

KIMITA, K; SHIMOMURA, Y; ARAI, T. Evaluation of customer satisfaction for PSS design. Journal of Manufacturing Technology Management, v. 20, n.5, p.654-673, 2009.

MONT, O. Product-service systems: reviewing achievements and refining the research agenda. Editorial. Journal of Cleaner Production v.14. p.1451-1454, 2006.

MORELLI, N. Designing product/service systems: a methodological exploration. Design Issues, v. 18, n.3, p.3-17, 2002.

MORELLI, N. Product-service systems, a perspective shift for designers: a case study: the design of a telecentre. Design Studies, v.24, p.73-99, 2003.

MORELLI, N. The system around the product: methodologies and experiences fo- 
cusing on material and immaterial aspects in design solutions. Conference paper, Futureground, Design research society international conference. 2005.

OZKARAMANLI, D.; DESMET, P. I knew I shouldn't, yet I did it again! Emotion-driven design as a means to motivate subjective well-being. International Journal of Design, 6(1), p.27-39, 2012.

OZKARAMANLI, D; OZCAN, E; DESMET, P. Capturing conflict experiences: five methods for identifying intrapersonal concern conflicts. Conference paper. The 9th International Conference on Design \& Emotion. p.317-324, 2014.

ROSEMAN, I; SMITH, C. Appraisal theory: overview, assumptions, varieties, controversies in SCHERER, Klaus et al. Appraisal processes in emotion. Oxford University press, 2001, p.3-19.

TONETTO, L. M. A perspectiva cognitiva no design para emoção: análise de concerns em projetos para a experiência. Strategic design research journal 5 (3), Unisinos, p. 99-106, 2012.

TONETTO, L. M.; COSTA, F.C.X. Design emocional: conceitos, abordagens e perspectivas de pesquisa. Strategic design research journal 4 (3), Unisinos, p.132-140, 2011.

TONETTO, L. M.; DESMET, P. Why we love or hate our cars: a qualitative approach to the development of a quantitative user experience survey. Applied Ergonomics, n.56, p.68-74, 2016. 